\title{
Aplicação do Custeio Baseado em Atividades em uma Pequena Propriedade Rural
}

\author{
Application of Activity Based Costing in a Rural Smallholding
}

\author{
Edson Roberto Macohon \\ Mestre em Administração pela \\ Universidade Regional de Blumenau - FURB \\ E-mail: edson.macohon@ contabilizacontabilidade.com.br \\ Endereço: Rua Antônio da Veiga, 140 - Sala D 202 - Bairro Victor Konder \\ Caixa Postal 1507 - CEP 89012-900 - Blumenau/SC - Brasil \\ Fone: 55 (47) 33210565 \\ Ilse Maria Beuren \\ Doutora em Controladoria e Contabilidade pela FEA/USP \\ Professora da Universidade Regional de Blumenau - FURB \\ E-mail: ilse@furb.br
}

Endereço: Rua Antônio da Veiga, 140 - Sala D 202 - Bairro Victor Konder

Caixa Postal 1507 - CEP 89012-900 - Blumenau/SC - Brasil

Fone: 55 (47) 33210565

\author{
João Felema \\ Universidade Estadual do Centro-Oeste (Unicentro) \\ Email: joaofelema@yahoo.com.br \\ Centro Integrado de Educação Municipal \\ Prolongamento da Av. São João, s/n \\ Barro Preto CEP 84400-000 Prudentópolis - PR - Brasil \\ Fone: 55 (42) 39081074 \\ Mario Kvasnei \\ Universidade Estadual do Centro-Oeste (Unicentro) \\ Email: decicirati@yahoo.com.br \\ Centro Integrado de Educação Municipal \\ Prolongamento da Av. São João, s/n \\ Barro Preto CEP 84400-000 Prudentópolis - PR - Brasil \\ Fone: 55 (42) 39081074
}

\section{RESUMO}

O artigo tem por objetivo descrever a aplicação de um sistema de gestão de custos baseado em atividades no âmbito de uma pequena propriedade rural. Trata-se de uma pesquisa exploratória, realizada por meio de um estudo de caso, com dados coletados através de visitas in loco, privilegiando a abordagem quantitativa. Os resultados apontam as etapas de aplicação do sistema de gestão de custos baseado em atividades, com destaque à identificação dos processos e atividades, levantamento dos recursos consumidos, identificação dos direcionadores de custos e de atividades e rastreamento dos recursos consumidos pelas atividades e estas pelos objetos de custeio. A análise indicou que a cultura com maior lucratividade foi o feijão, seguida pela soja e por último, com resultado negativo, o milho. Dentre as três culturas a soja é que teve menor custo de produção por hectare. As atividades que consumiram mais recursos nas três 
culturas foram o plantio e a colheita. Conclui-se, com base nos resultados encontrados, que a aplicação do custeio $\mathrm{ABC}$ em uma pequena propriedade rural, embora aqui restrita a um estudo de caso e, por isso, não se pode generalizar as conclusões, o modelo é viável enquanto sistema de gestão de custos.

Palavras-chave: Custeio baseado em atividades. Direcionadores de custos. Pequena propriedade rural.

\begin{abstract}
The objective of this article is to describe the application of a management system of activity based costing in a rural smallholding. This is an exploratory research conducted through a case study, with data collected from in loco visits, using a quantitative approach. The results show the application stages of the management system of activity based costing, highlighting the processes and activities, the surveying of the resources consumed, the identification of direction drivers for costs and activities; as well as the tracing of resources consumed through activities and these by the cost objects. The analysis indicated the most lucrative crop to be bean cultivation, followed by soy and last, with a negative return, sweet corn. From the three crops soy has the lowest production cost per hectare. The activities which most consumed resources for cultivation of the three crops were the sowing and reaping. It was concluded, based on the results obtained, that the application of $\mathrm{ABC}$ in a small rural smallholding, even though this research was restricted to a case study and therefore cannot draw general conclusions, that the model is viable for a management system for costs.
\end{abstract}

Keywords: Activity based costing. Cost drivers. Rural smallholding.

\title{
1 INTRODUÇÃO
}

Há inúmeras situações adversas na qual a agricultura está inserida, podendo se destacar: surgimento de tecnologias com preços não acessíveis, políticas governamentais de apoio não favoráveis, escassez de recursos financeiros, condições climáticas desfavoráveis, preços baixos dos produtos agrícolas, falta de capacitação em gestão dos agricultores para administrarem suas propriedades rurais.

Outra deficiência na atividade rural é a falta de conhecimento da contabilidade enquanto instrumento de gestão. A contabilidade na atividade rural é pouco utilizada, principalmente pelos pequenos produtores rurais.

Marion (1996) atribui o pouco uso da contabilidade rural à ausência dessa disciplina nos cursos de pós-graduação em nível de lato sensu e stricto sensu no Brasil, trazendo enormes prejuízos à administração rural e agroindustrial. No campo de pesquisas científicas em administração e contabilidade rural, deixa muito a desejar em comparação com os demais países em desenvolvimento.

Uma das preocupações na área rural é o custo, pois é imprescindível o seu conhecimento para o adequado gerenciamento da atividade rural. Segundo Souza et al. (1992, p. 192), "custo de produção, da mesma forma que a contabilidade, é um componente importante dentro do controle de toda a empresa agrícola”.

Os relatórios contábeis, bem como os sistemas de custeio, são importantes instrumentos de gerenciamento da atividade rural, possibilitando o conhecimento dos custos relativos à produção agrícola. Para Souza et al. (1992, p. 165), "a contabilidade, quando direcionada de maneira adequada, é uma fonte inesgotável de dados que pode ser explorada para colocar a empresa em condições de competir, com as demais em seu gênero".

Com as inovações tecnológicas implantadas nas propriedades rurais durante as últimas décadas, criou-se a necessidade de implantação de novos sistemas de custeio 
que se adaptassem melhor à realidade das empresas, pois os custos indiretos tornaramse mais representativos na composição do custo total dos produtos.

Para Leone (1997), uma das razões para o aparecimento de um novo sistema de custos baseia-se na evolução tecnológica, que alterou bastante a composição dos custos dos fatores de produção, decorrente principalmente do aumento dos custos relacionados à depreciação e manutenção dessas novas tecnologias.

As empresas vêm investindo sobremaneira em automação, além de estarem mudando profundamente os seus processos de produção. Novas formas de gerenciamento foram criadas e aperfeiçoadas para assegurar a continuidade das empresas em um ambiente mais concorrido e internacionalizado. Não está sendo diferente no setor agrícola, em que empresas rurais e até pequenas propriedades rurais familiares tiveram que se modernizar para competir no mercado.

Leone (1997) ressalta a importância da contabilidade de custos neste cenário de mudanças e o surgimento do custeio baseado em atividades (Activity Based Costing $\mathrm{ABC})$.

A contabilidade teve que rever seus sistemas e seus critérios, para produzir informações mais precisas, oferecendo base às decisões gerenciais. Neste contexto surgiu o custeio $\mathrm{ABC}$, que pretende atender os gestores em suas novas necessidades.

Embora a produção científica sobre aspectos conceituais do custeio $\mathrm{ABC}$ seja ampla, não se dispõe de produção tão profícua sobre a aplicação desse sistema em diversos tipos de negócios e, menos ainda, no agronegócio. Visando a análise da aplicação do sistema de custeio $\mathrm{ABC}$ em uma pequena propriedade rural, o presente trabalho pretende responder a seguinte questão de pesquisa: Como se aplica um sistema de gestão de custos baseado em atividades no âmbito de uma na pequena propriedade rural?

Assim, o objetivo geral do artigo é descrever a aplicação de um sistema de gestão de custos baseado em atividades no âmbito de uma pequena propriedade rural. Em consonância com a questão de pesquisa e do objetivo geral, foram propostos os seguintes objetivos específicos: a) descrever os processos e atividades de produção das culturas do feijão, milho e soja; b) levantar os recursos consumidos nas culturas; c) identificar os direcionadores dos recursos e das atividades; d) mensurar os custos das culturas; e) analisar os resultados das culturas do feijão, milho e soja.

A relevância do artigo está diante dos problemas que se revelam no âmbito do agronegócio em geral e da pequena propriedade rural em particular. Dessa buscou-se extrair a essência para elaborar o sistema que se denominou de sistema de gestão de custos baseado em atividades, fundamentado no custeio ABC. Pretende-se contribuir com o aprofundamento das discussões sobre a aplicabilidade do custeio $\mathrm{ABC}$ e a disseminação desse sistema em uma atividade que não tem recebido a atenção necessária diante do novo cenário de competição que se apresenta neste setor.

$\mathrm{O}$ artigo está organizado em cinco seções, iniciando com essa introdução. Na seqüência faz uma incursão teórica nos fundamentos do custeio $\mathrm{ABC}$, com destaque aos processos, recursos, atividades, direcionadores e objetos de custeio. Em seguida evidencia o método e os procedimentos metodológicos da pesquisa. Após apresenta os resultados da pesquisa, além das considerações finais ao estudo realizado.

\section{FUNDAMENTOS DO CUSTEIO BASEADO EM ATIVIDADES}

$O$ custeio $A B C$ surgiu com influência de um cenário em que a competitividade e as tecnologias cresciam rapidamente e, além disto, se estabelecia uma nova visão de gestão de negócios. As determinantes fundamentais foram: a competição global, multiplicidade de produtos no mercado, desenvolvimento de sistemas informatizados, 
necessidade de informações precisas por parte da gerência e a evolução tecnológica que trouxe um conceito mais significativo aos custos indiretos.

Segundo Ching (2001, p. 41), o custeio ABC "é um método de rastrear os custos de um negócio ou departamento para as atividades realizadas e de verificar como estas atividades estão relacionadas para a geração de receita e consumo dos recursos". Kaplan e Cooper (1999, p. 101) explicam que:

o método $\mathrm{ABC}$ representa uma nova maneira de pensar. Os sistemas de custeio tradicionais procuravam responder à seguinte questão: Como é que a organização vai imputar os custos para efeitos de informação financeira e para controle dos custos dos departamentos? O método ABC parte de questões completamente diferentes: Que atividades se realizam na organização? Quanto custa realizar essas atividades? Porque é que a organização necessita realizar essas atividades ou processos? Que parte ou quantidade dessas atividades requerem os produtos, serviços ou clientes da organização?.

$\mathrm{O}$ sistema $\mathrm{ABC}$ tem como premissa fundamental o fato de os custos indiretos serem causados por atividades desenvolvidas durante o processo de produção. $\mathrm{O}$ relacionamento entre custos e atividades é realizado através dos direcionadores de custos e o relacionamento entre as atividades com os produtos é realizado através dos direcionadores de atividades (SHANK e GOVINDARAJAN, 1995; KAPLAN e COOPER, 1998; ATKINSON et al., 2000; GARRISON e NOREEN, 2001).

O foco central do (ABC) são as atividades. Através desta sistemática, entende-se que são elas as consumidoras de recursos e, posteriormente, essas atividades custeadas são alocadas aos produtos. O rastreamento feito nas atividades identifica as diversas rotas de consumo e quais as atividades que consomem mais recursos.

Nakagawa (2001, p. 39) reitera o papel das atividades como consumidoras dos recursos de fabricação. Ressalta que no " $\mathrm{ABC}$, assume-se como pressuposto que os recursos de uma empresa são consumidos por suas atividades e não pelos produtos que ela fabrica. Os produtos surgem como conseqüência das atividades consideradas estritamente necessárias para fabricá-los e/ou comercializá-los".

$\mathrm{O}$ custeio $\mathrm{ABC}$ busca a análise e o gerenciamento das atividades que consomem mais recursos em uma empresa. A estrutura do $\mathrm{ABC}$ é sustentada pelas atividades, que é o próprio objeto do sistema de custeio. Uma atividade engloba um conjunto de ações em uma empresa, que através de um processo visam produzir um produto ou um serviço. A atividade é definida como sendo uma conjunção coordenada de recursos (mão-de-obra, materiais, tecnologia e ambiente) que visa à produção de um determinado bem ou serviço (NAKAGAWA, 2001).

$\mathrm{O}$ custeio $\mathrm{ABC}$ permite uma visão abrangente em relação às atividades e suas formas de consumir recursos. Sendo assim, proporciona ao gestor identificar quais as atividades que consomem mais recursos no decorrer de suas operações e quais que vêm a desperdiçar mais.

Brimson (1996, p. 41) afirma que "as informações por atividades permitem aos gerentes identificar e eliminar os desperdícios. Também confirma o progresso em remover os desperdícios das atividades operacionais".

As etapas no processo produtivo de um produto constituem o primeiro passo para iniciar o custeamento com base em atividades. A identificação das etapas consiste no levantamento e na escolha das atividades que melhor representam o consumo dos recursos. É realizada a classificação das atividades de acordo com a frequiência em que ocorrem e ao estágio do processo produtivo a que pertencem, proporcionando o mapeamento do processo produtivo (MAHER, 2001). 
Com o crescimento relativo dos gastos indiretos, o custeio por produto, por departamento ou por qualquer outro objeto de custeio passa a ser crescentemente distorcido por eventuais deficiências de rateio. Nakagawa (2001, p. 30) ressalta que, idealmente, todos os custos "deveriam ser diretamente apropriados às atividades e aos produtos, mas, à medida que as tecnologias evoluem cada vez mais, os custos vão tornando-se indiretos. [...] o ABC é um facilitador para apropriação direta dos custos indiretos e o rateio deve ser usado só em última instância".

$\mathrm{O}$ custeio $\mathrm{ABC}$ utiliza a técnica de rastreamento dos recursos e das atividades com o objetivo de identificar, classificar e mensurar os custos, para refletir a situação real da estrutura de custos em cada atividade e produto. Desse modo, o passo seguinte é a definição dos direcionadores de custos. Garrison e Noreen (2001) destacam que os direcionadores de custos indicam o índice que origina os custos indiretos, fazendo com que as atividades agreguem valor e sejam realizadas. Uma mesma atividade pode ter vários direcionadores de custos.

Os direcionadores de custos demonstrarão o quanto as atividades consomem os recursos e determinarão a influência destes recursos que cada atividade utiliza. Martins (2001) define direcionador de custos como o fator que determina a ocorrência de uma atividade.

Como as atividades exigem recursos para serem realizadas, deduz-se que o direcionador é a verdadeira causa dos custos. Portanto, o direcionador deve refletir a causa básica da atividade e, conseqüentemente, da existência de seus custos.

Os direcionadores de custos são fatores que geram ou influenciam o nível dos gastos de uma atividade ou de um objeto de custeio. Por isso são instrumentos de rastreamento e de quantificação dos gastos de atividades e dos objetos que se deseja custear. Sakurai (1997) afirma que direcionadores de custos são quaisquer fatores que causam alterações no custo das atividades. Considerando que as atividades e direcionadores de custos constituem a base para se fazer o custeamento dos produtos, Kaplan e Cooper (1998) destacam que se pode interpretar a atividade como uma combinação do uso de recursos humanos, tecnológicos e de materiais para a produção de bens e ou serviços.

Ressalta-se que os direcionadores de custos levam em conta as atividades desenvolvidas na fabricação dos produtos ou serviços, nas vendas, na administração, entre outros, pois, admite-se que todas consomem recursos, sendo imprevisível o cálculo desses recursos para se saber o custo total dos produtos. Na Figura 1 apresentase uma visão geral do processo de alocação dos custos às atividades e destas aos produtos, conforme preconizado no custeio ABC. 


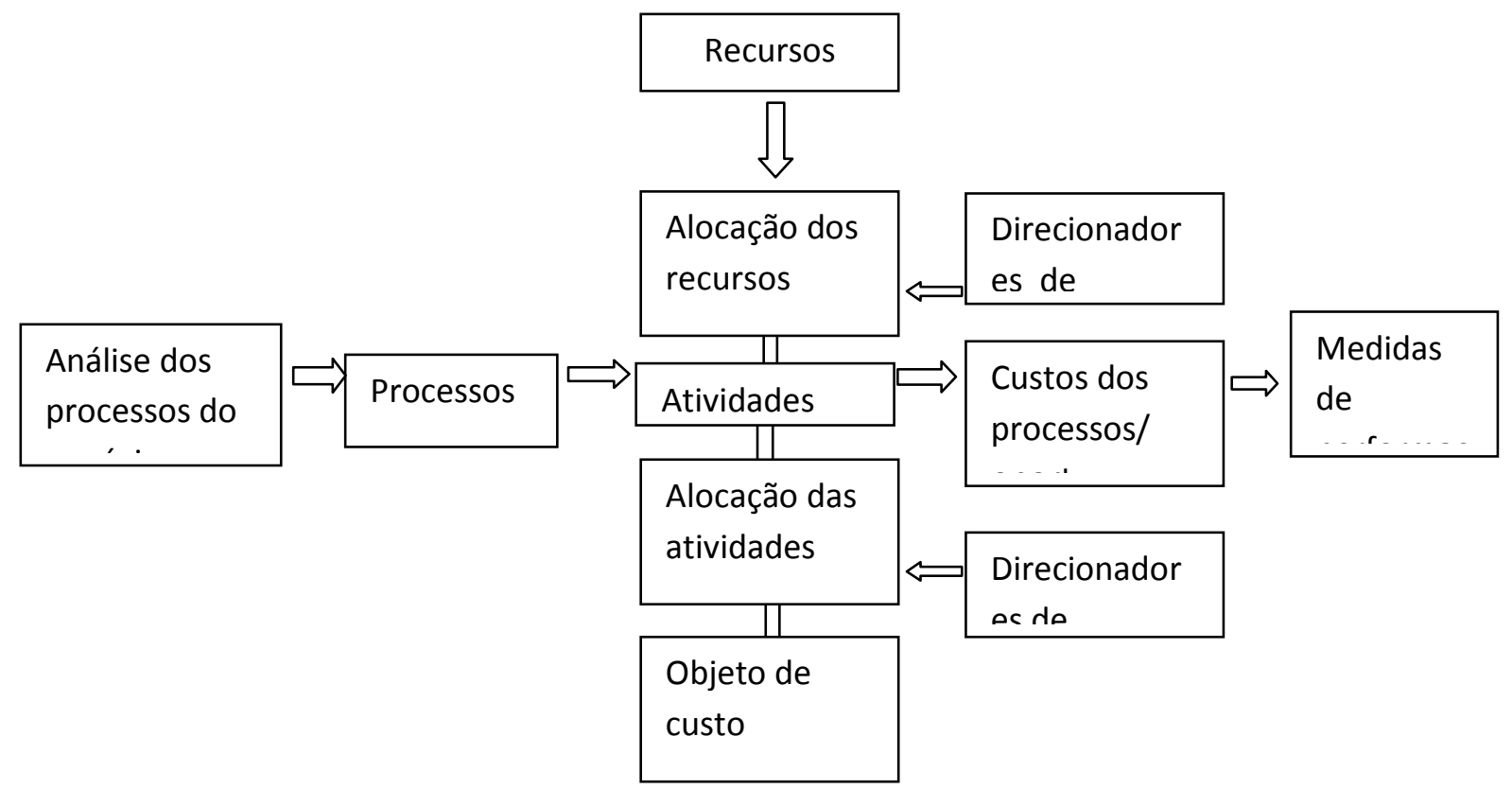

Figura 1 - Visão da alocação dos custos

Fonte: Domenico (www.unicamp.br).

Observa-se na Figura 1 que o primeiro direcionador irá mensurar o quanto a atividade consumiu de recursos e o segundo direcionador identificará quanto o objeto de custeio consumiu de recursos da atividade. Essa diferenciação é justificada pelo fato de que uma mesma atividade pode acontecer para diferentes objetos de custeio. O segundo direcionador mensurará o custo do produto e permitirá analisar os sub-processos de uma atividade, que são as menores tarefas realizadas durante a atividade.

Os direcionadores de custos ou cost drivers têm influência direta sobre as atividades e conseqüentemente nos produtos. Para Nakagawa (2001) todo fator que altere o custo de uma atividade é um cost driver. Através dos direcionadores de custos o custeio ABC tem por meta encontrar a verdadeira causa dos custos, ou seja, quais e quanto as atividades consomem de recursos, posteriormente, quanto o produto final recebe de custos em seu processo produtivo.

Maher (2001) adverte sobre a necessidade de análise das relações possíveis na seleção dos direcionadores de custos para as atividades e destas aos produtos. Cita as relações que seguem: a) a relação causal - o direcionador de custos deve apresentar grau de correlação entre o fato que dá origem ao custo indireto e à atividade; b) os benefícios gerados - um direcionador de custos mede o desempenho da atividade, observando a relação custo/benefício; c) a razoabilidade - os custos indiretos não são alocados aos produtos e ou serviços com base em um único direcionador, isso explica o porquê de as atividades poderem ter mais de um direcionador de custo.

A concepção do custeio ABC pressupõe não apenas o custeio das atividades e dos objetos de custeio, mas também o gerenciamento das atividades, o que deu origem ao termo denominado gerenciamento baseado em atividades (Activity Based Management - ABM).

Neste sentido é que as etapas apresentadas devem conduzir ao melhor aproveitamento das informações, para que ocorra o gerenciamento do empreendimento a partir das atividades, seja sob o ponto de vista dos processos ou dos custos incorridos na realização das atividades necessárias para a geração dos produtos. 


\section{MÉTODO E PROCEDIMENTOS DA PESQUISA}

A presente pesquisa caracteriza-se como exploratória e foi realizada por meio de um estudo de caso. Para Raupp e Beuren (2004, p. 80), a "pesquisa exploratória consiste no aprofundamento de conceitos preliminares sobre determinada temática não contemplada de modo satisfatório anteriormente. Assim, contribui para o esclarecimento de questões

superficialmente abordadas sobre o assunto".

O estudo de caso, segundo Fachin (2002, p. 42), caracteriza-se como "um estudo intensivo. É levado em consideração, principalmente, a compreensão, como um todo, do assunto investigado. Todos os aspectos do caso são investigados. Quando o assunto é intensivo podem até aparecer relações que de outra forma não seriam descobertas".

Segundo Merrian (1998), o estudo de caso implica exame de um fenômeno específico, tal como um programa, um acontecimento, uma pessoa, um processo, uma instituição ou um grupo social. Gil (1999, p. 72) define estudo de caso como o "estudo profundo e exaustivo de um ou poucos objetos, de maneira a permitir o seu conhecimento amplo e detalhado, tarefa praticamente impossível mediante os outros tipos de delineamento considerados".

A pesquisa foi realizada em uma pequena propriedade rural no município de Prudentópolis, estado do Paraná. A coleta de dados teve a seguinte estrutura seqüencial: caracterização dos processos das culturas foco de análise; identificação dos elementos e

custos e seus respectivos valores; averiguação das atividades relevantes relacionadas; verificação do relacionamento entre as atividades e os custos; determinação dos direcionadores de custos que se relacionam às atividades; determinação dos direcionadores de atividades que se relacionam aos objetos de custeio; custeamento propriamente dito, das atividades e das culturas de soja, feijão e milho.

A abordagem da pesquisa é predominantemente quantitativa. Conforme Richardson (1999, p. 70), a abordagem quantitativa caracteriza-se pelo "emprego da quantificação tanto nas modalidades de coleta de informações, quanto no tratamento delas por meio de técnicas estatísticas, desde as mais simples, como percentual, média, desvio-padrão, às mais complexas, como coeficiente de correlação, análise de regressão".

\section{DESCRIÇÃO E ANÁLISE DOS RESULTADOS}

$\mathrm{Na}$ descrição e análise dos resultados inicia-se com a apresentação da propriedade rural objeto de estudo de caso. Na sequiência abordam-se os elementos de custos e seus respectivos valores, o mapeamento das atividades, os direcionadores de recursos e de atividades, o custeio dos objetos alvo e a análise dos resultados das culturas.

\subsection{APRESENTAÇÃO DA PROPRIEDADE RURAL}

A propriedade rural estudada, por questão de sigilo, não tem aqui sua denominação revelada. Está localizada à $23 \mathrm{~km}$ do município de Prudentópolis (região Centro-Sul do Paraná) e possui área total de aproximadamente 25 hectares, contudo 22 hectares são terras cultiváveis. Trata-se de uma propriedade familiar juridicamente classificada como pessoa física. Os atuais proprietários administram a fazenda desde a década de 70, época em que adquiriram a propriedade.

No início o negócio da propriedade rural era constituído pela produção de feijão, milho e hortaliças. Possuía área de 17 hectares para produção de feijão e o restante para produção de milho e hortaliças. Devido ao crescimento do agronegócio e a consequente 
expansão do plantio de soja nas pequenas propriedades rurais, a produção da propriedade foi diversificada a partir da década de 90.

O expressivo crescimento da produção de soja no Brasil, nas últimas quatro décadas, determinou importantes mudanças do agronegócio. Ela foi responsável pela aceleração da mecanização das lavouras brasileiras, pela modernização do sistema de transporte, pela expansão da fronteira agrícola, pelo incremento do comércio internacional, pela interiorização da população brasileira, bem como impulsionou a agroindústria nacional.

Com este novo cenário da agricultura brasileira, a propriedade começou a produzir soja, sendo o plantio entre os meses de novembro a janeiro, com a colheita entre os meses de abril a maio, dependendo das intempéries climáticas.

Tendo como estratégia a diversificação, também produz feijão. A região centrosul do estado do Paraná é conhecida nacionalmente como uma das maiores produtoras de feijão do Brasil. O plantio do feijão nesta região se dá principalmente no mês de setembro e a colheita no mês de dezembro.

Além disso, produz também milho. Devido a sua utilização para a ração animal como base alimentar na pecuária, avicultura, suinocultura e até piscicultura, a produção de milho vem aumentando ano após ano. O milho tem evoluído como cultura comercial. O plantio do milho é realizado coincidentemente com o período do feijão, mês de setembro e sua colheita em janeiro.

No período em que não há cultivo de soja, feijão e milho, os proprietários realizam o plantio de azevém ou aveia, culturas que servem para fixar a terra contra a erosão. Essas culturas também podem ser utilizadas como pastagem para o gado na época de inverno.

\subsection{ELEMENTOS DE CUSTOS E SEUS RESPECTIVOS VALORES}

A propriedade rural em estudo, para realizar o cultivo de soja, feijão e milho, conta com os bens arrolados no Quadro 1.

\begin{tabular}{|c|l|c|cc|}
\hline Quant & \multicolumn{1}{|c|}{ Descrição } & Ano/ fabricação & \multicolumn{2}{c|}{ Valor/mercado } \\
\hline 1 & Trator & 2004 & $\mathrm{R} \$$ & $95.000,00$ \\
\hline 1 & Plantadeira & 1998 & $\mathrm{R} \$$ & $25.000,00$ \\
\hline 1 & Pulverizador & 1988 & $\mathrm{R} \$$ & $6.000,00$ \\
\hline 1 & Grade niveladora & 1996 & $\mathrm{R} \$$ & $4.800,00$ \\
\hline 1 & Vicão & 2004 & $\mathrm{R} \$$ & $2.200,00$ \\
\hline 1 & Galpão de alvenaria 90 m2 & & $\mathrm{R} \$$ & $6.000,00$ \\
\hline
\end{tabular}

Quadro 1 - Bens da empresa relativos ao cultivo de soja, feijão e milho

Fonte: dados da pesquisa.

Os bens arrolados foram quantificados monetariamente a valor de mercado, considerando o seu ano de fabricação. Para a depreciação foi considerado o valor residual (valor que se supõe recuperar na reposição dos bens), além da vida útil desses bens para as referidas culturas. No Quadro 2 demonstra-se a depreciação dos equipamentos e edificações.

\begin{tabular}{|l|l|l|l|l|l|l|}
\hline Descrição & $\begin{array}{l}\text { Valor/merca } \\
\text { do }\end{array}$ & $\begin{array}{l}\text { Residua } \\
\mathbf{l}\end{array}$ & Residual & $\begin{array}{l}\text { Valor } \\
\text { p/depreciar }\end{array}$ & Vida útil & $\begin{array}{l}\text { Depreciação } \\
\text { hora/ano }\end{array}$ \\
\hline Equipamentos/Edif & $\mathrm{R} \$$ & $\%$ & $\mathrm{R} \$$ & $\mathrm{R} \$$ & Hrs/anos & $\mathrm{R} \$$ \\
\hline Trator & $95.000,00$ & 17,5 & $16.625,00$ & $78.375,00$ & 12.500 & 6,27 \\
\hline Plantadeira & $25.000,00$ & 12,5 & $3.125,00$ & $21.875,00$ & 2.000 & 10,94 \\
\hline Pulverizador & $6.000,00$ & 7,5 & 450,00 & $5.550,00$ & 2.000 & 2,78 \\
\hline
\end{tabular}




\begin{tabular}{|l|l|l|l|l|l|l|}
\hline Grade niveladora & $4.800,00$ & 7,5 & 360,00 & $4.440,00$ & 2.500 & 1,78 \\
\hline Vicão & $2.200,00$ & 7,5 & 165,00 & $2.035,00$ & 1.750 & 1,16 \\
\hline Galpão Alvenaria & $6.000,00$ & 35,0 & $2.100,00$ & $3.900,00$ & 32,5 anos & $120,00 /$ ano \\
\hline
\end{tabular}

Quadro 2 - Depreciação dos equipamentos e edificações

Fonte: dados da pesquisa.

Para realizar a depreciação destes itens adotou-se a seguinte metodologia: cálculo do valor residual dos itens a serem depreciados, sendo que os percentuais do valor residual variam de equipamento para equipamento, conforme o Quadro 2. Fazendo a subtração do valor de mercado ao valor residual se obterá o valor a ser depreciado, que em seguida é dividido pelo número de horas estimadas de trabalho, obtendo assim a depreciação-hora, que serão alocadas para as atividades.

Há na propriedade um galpão de alvenaria de $90 \mathrm{~m} 2$, o qual é utilizado para guardar os maquinários agrícolas. O galpão tem um valor de mercado de $\mathrm{R} \$ 6.000,00$. O galpão de alvenaria, após totalmente depreciado, pressupõe-se que ainda resta um percentual de $35 \%$ do valor de mercado. Efetuando este cálculo (R $\$ 6.000,00 * 35 \%$ ) obtém-se um valor residual de $\mathrm{R} \$ 2.100,00$. Dessa forma encontra o valor a ser depreciado ( $\mathrm{R} \$ 6.000,00-\mathrm{R} \$ 2.100,00)$. A vida útil de um galpão de alvenaria é de aproximadamente 32 anos e seis meses, realizando a operação ( $\mathrm{R} \$ 3.900,00 / 32,5)$ têmse à depreciação anual de $\mathrm{R} \$ 120,00$. A depreciação da edificação foi rateada por hora, utilizando-se o mesmo critério adotado para as máquinas e equipamentos.

No Quadro 3 apresenta-se o custo da mão-de-obra com os respectivos encargos sociais e trabalhistas da propriedade, especificamente para as três culturas.

\begin{tabular}{|l|c|c|}
\hline \multirow{2}{*}{ Descrição } & Adições & Total \\
\cline { 2 - 3 } & $\%$ & $\mathrm{R} \$$ \\
\hline Salário mínimo & $0 \%$ & 350,00 \\
\hline Piso da categoria & $30 \%$ & 105,00 \\
\hline Salário base (R\$) & ---- & 455,00 \\
\hline $13^{\circ}$ salário & $1 / 12$ & 37,92 \\
\hline Férias & $1 / 12$ & 37,92 \\
\hline $1 / 3$ sobre férias & $33,33 \%$ (sobre férias) & 12,64 \\
\hline Sub total & & $\mathbf{5 4 3 , 4 8}$ \\
\hline INSS & $25,2 \%$ & 136,95 \\
\hline FGTS & $8,5 \%$ & 46,20 \\
\hline Total & & $\mathbf{7 2 6 , 6 2}$ \\
\hline
\end{tabular}

Quadro 3 - Custo da mão-de-obra com encargos sociais e trabalhistas

Fonte: dados da pesquisa.

A mão de obra utilizada na produção das três culturas é inteiramente familiar. Para se obter o custo hora-homem, foi considerado o valor do salário mínimo (R\$ $350,00)$, mais $30 \%$ do piso da categoria ( $\mathrm{R} \$ 350,00+30 \%)$, chegando ao salário base de $\mathrm{R} \$ 455,00$. Além disso, foram adicionados INSS, FGTS, férias e $13^{\circ}$ salário, de acordo com a legislação trabalhista em vigor.

Para apropriar devidamente a mão-de-obra, foi realizada uma pesquisa no Sindicato dos Trabalhadores Rurais. Um empregado rural trabalha em média 176 horas mensal.

Dividindo a remuneração mensal de $\mathrm{R} \$ 726,62$ pelo número médio de horas que um funcionário rural trabalha durante o mês ( $\mathrm{R} \$ 726,62$ / 176 horas), chega-se a um custo-hora-homem de $\mathrm{R} \$ 4,13$. 
Durante o processo produtivo das culturas, o proprietário realizou uma troca de óleos e filtros no valor de $\mathrm{R} \$ 105,00$. Para as três culturas (feijão, milho e soja) houve um consumo de 133 horas-máquinas. Segundo o manual técnico do trator são recomendadas que sejam feitas trocas de óleos lubrificantes e filtros entre 120 e 150 horas-máquinas. Dessa forma, o custo-hora de óleos lubrificantes e filtros obteve-se da divisão de $\mathrm{R} \$ 105,00$ / 133 horas-máquina, resultando em um valor de $\mathrm{R} \$ 0,79$ por hora de óleos lubrificantes e filtros.

O calcário ou outros corretivos aplicados que beneficiarão vários períodos devem ser amortizados e alocados como custo de acordo com a quantidade de períodos que irão beneficiar. Com base em instruções agronômicas o calcário aplicado perdura por 4 anos, ou seja, 25\% do total da compra de calcário, o que corresponde a 3,75 toneladas-ano, equivalente a um custo de $\mathrm{R} \$ 157,50$ por ano.

\subsection{CUSTEIO DAS CULTURAS DE SOJA, FEIJÃO E MILHO}

Após o levantamento dos elementos de custos e seus respectivos valores, efetuou-se o custeio das culturas de soja, feijão e milho. Inicialmente realizou-se o mapeamento das atividades de cada cultura, após definiram-se os respectivos direcionadores de recursos e de atividades e, por último, procedeu-se o custeio dos objetos alvo.

Os direcionadores de custos são os principais elementos do custeio $\mathrm{ABC}$, porque determinam o consumo de recursos para cada atividade. Na propriedade em estudo, os direcionadores de custos foram definidos em função do consumo dos recursos pelas atividades e, por sua vez, os direcionadores de atividades pelos hectares de produção de cada cultura.

No Quadro 4 apresenta-se o cálculo do custo das atividades relacionadas à cultura da soja, evidenciando-se as atividades, os direcionadores de recursos e de atividades com as respectivas distribuições de valores e, por último, o custeio da cultura de soja. 


\begin{tabular}{|c|c|c|c|c|c|c|c|c|c|c|}
\hline \multirow[b]{3}{*}{ Atividades } & \multirow{3}{*}{$\begin{array}{l}\text { Direc. } \\
\text { de } \\
\text { custos }\end{array}$} & \multirow[b]{3}{*}{ Quant } & \multicolumn{5}{|c|}{ Recursos } & \multirow{2}{*}{$\begin{array}{l}\text { Total } \\
\text { da } \\
\text { atividade }\end{array}$} & \multirow{2}{*}{$\begin{array}{l}\text { Custo } \\
\text { por } \\
\text { hectare }\end{array}$} & \multirow[b]{3}{*}{$\%$} \\
\hline & & & $\begin{array}{c}\text { de- } \\
\text { obra }\end{array}$ & Materiais & Combustível & Depreciação & Óleos/filtros & & & \\
\hline & & & $\%$ & $\%$ & $\%$ & $\%$ & $\%$ & $\mathbf{R} \$$ & $\mathbf{R} \$$ & \\
\hline $\begin{array}{l}\text { Compra } \\
\text { calcário }\end{array}$ & $\mathrm{n}^{\circ} \mathrm{ha}$ & 9,68 & 7,3 & 2,8 & 3,6 & 2,9 & 4,2 & 205,94 & 21,27 & 2,4 \\
\hline $\begin{array}{l}\text { Grade } \\
\text { niveladora }\end{array}$ & $\mathrm{n}^{\circ}$ ha & 9,68 & 4,9 & 0,0 & 4,9 & 4,2 & 5,6 & 54,12 & 5,59 & 0,6 \\
\hline $\begin{array}{l}1^{\circ} \text { Pulv. } \\
\text { (secagem) }\end{array}$ & $\mathrm{n}^{\circ}$ ha & 9,68 & 4,9 & 5,0 & 4,9 & 4,6 & 5,6 & 336,12 & 34,72 & 3,9 \\
\hline $\begin{array}{l}\text { Efetuar o } \\
\text { plantio }\end{array}$ & $\mathrm{n}^{\circ}$ ha & 9,68 & 48,8 & 69,7 & 35,1 & 42,1 & 28,2 & $4.387,75$ & 453,28 & 51,0 \\
\hline $\begin{array}{l}2^{\circ} \text { pulv. } \\
\text { herbicida }\end{array}$ & $\mathrm{n}^{\circ} \mathrm{ha}$ & 9,68 & 4,9 & 1,4 & 7,0 & 6,6 & 8,0 & 150,61 & 15,56 & 1,8 \\
\hline $\begin{array}{l}3^{\circ} \text { pulv. } \\
\text { herbicida }\end{array}$ & $\mathrm{n}^{\circ} \mathrm{ha}$ & 9,68 & 4,9 & 1,4 & 7,0 & 6,6 & 8,0 & 150,61 & 15,56 & 1,8 \\
\hline $\begin{array}{l}4^{\circ} \text { pulv. } \\
\text { adubo foliar }\end{array}$ & $\mathrm{n}^{\circ}$ ha & 9,68 & 4,9 & 2,8 & 7,5 & 6,6 & 8,0 & 232,90 & 24,06 & 2,7 \\
\hline $\begin{array}{l}5^{\circ} \text { pulv. } \\
\text { adubo foliar }\end{array}$ & $\mathrm{n}^{\circ} \mathrm{ha}$ & 9,68 & 4,9 & 2,8 & 7,5 & 6,6 & 8,0 & 232,90 & 24,06 & 2,7 \\
\hline $\begin{array}{l}6^{\circ} \text { pulv. } \\
\text { inseticida }\end{array}$ & $\mathrm{n}^{\circ} \mathrm{ha}$ & 9,68 & 4,9 & 1,8 & 7,5 & 6,6 & 8,0 & 180,40 & 18,64 & 2,1 \\
\hline $\begin{array}{l}7^{\circ} \text { pulv. } \\
\text { ferrugem } \\
\text { asiática }\end{array}$ & $\mathrm{n}^{\circ} \mathrm{ha}$ & 9,68 & 4,9 & 10,5 & 7,5 & 6,6 & 8,0 & 666,90 & 68,89 & 7,8 \\
\hline $\begin{array}{l}8^{\circ} \text { pulv. } \\
\text { inseticida }\end{array}$ & $\mathrm{n}^{\circ}$ ha & 9,68 & 4,9 & 1,8 & 7,5 & 6,6 & 8,0 & 180,40 & 18,64 & 2,1 \\
\hline $\begin{array}{l}\text { Colheita } \\
\text { (tercerização) }\end{array}$ & $\mathrm{n}^{\circ} \mathrm{ha}$ & 9,68 & & & & & & $1.364,00$ & 140,91 & 16 \\
\hline $\begin{array}{l}\text { Frete } \\
\text { (tercerização) }\end{array}$ & $\mathrm{n}^{\circ} \mathrm{ha}$ & 9,68 & & & & & & 381,00 & 39,36 & 4,5 \\
\hline Total & & & 100 & 100 & 100 & 100 & 100 & $8.523,64$ & 880,54 & 100 \\
\hline
\end{tabular}

Quadro 4 - Cálculo do custo das atividades relacionadas à cultura da soja

Fonte: dados da pesquisa.

A cultura da soja se compõe de quatro processos na produção: preparo do solo, plantio, tratamento de cultura em formação e colheita + frete. Esses processos se subdividem em atividades, expostas no Quadro 4. A área cultivável de soja é equivalente a 9,68 hectares.

Os recursos mais representativos em termos de valores foram os materiais, com $66 \%$ da estrutura total de custos. O levantamento de custos por atividades na cultura da soja destaca os processos mais consumidores de recursos, são eles: o plantio e a colheita (67\% dos custos de produção). Destaca-se com 51\% o plantio, a colheita com $16 \%$ e a pulverização para prevenção contra a ferrugem asiática com $8 \%$.

No Quadro 5 apresenta-se o cálculo do custo das atividades relacionadas à cultura do feijão, evidenciando-se as atividades, os direcionadores de recursos e de atividades com as respectivas distribuições de valores e, por último, o custeio da cultura de feijão.

\begin{tabular}{|c|c|c|c|c|c|c|c|c|c|c|}
\hline \multirow[b]{3}{*}{ Ativividades } & \multirow{3}{*}{$\begin{array}{l}\text { Direc. } \\
\text { de } \\
\text { custos }\end{array}$} & \multirow[b]{3}{*}{ Quant } & \multicolumn{5}{|c|}{ Recursos } & \multirow{2}{*}{$\begin{array}{l}\text { Total } \\
\text { da } \\
\text { atividade }\end{array}$} & \multirow{2}{*}{$\begin{array}{l}\text { Custo } \\
\text { por } \\
\text { hectare }\end{array}$} & \multirow[b]{3}{*}{$\%$} \\
\hline & & & $\begin{array}{c}\text { Mão- } \\
\text { de- } \\
\text { obra }\end{array}$ & Materiais & Combust. & Depr. & Óleos/filtros & & & \\
\hline & & & $\%$ & $\%$ & $\%$ & $\%$ & $\%$ & $\mathbf{R} \$$ & $\mathbf{R} \$$ & \\
\hline $1^{\circ}$ pulv. (secagem) & $\mathrm{n}^{\circ} \mathrm{ha}$ & 10,9 & 6,5 & 3,0 & 6,5 & 5,9 & 7,69 & 392,23 & 35,98 & 2,6 \\
\hline Plantio & $\mathrm{n}^{\circ} \mathrm{ha}$ & 10,9 & 48,4 & 49,3 & 46,7 & 53,7 & 38,46 & $5.815,56$ & 533,54 & 38,6 \\
\hline $2^{\circ}$ pulv. herbicida & $\mathrm{n}^{\circ} \mathrm{ha}$ & 10,9 & 6,5 & 8,8 & 6,7 & 5,9 & 7,69 & $1.007,93$ & 92,47 & 6,7 \\
\hline $3^{\circ}$ pulv. inseticida & $\mathrm{n}^{\circ}$ ha & 10,9 & 6,5 & 2,0 & 6,7 & 5,9 & 7,69 & 293,93 & 26,97 & 2,0 \\
\hline $4^{\circ}$ pulv. inseticida & $\mathrm{n}^{\circ}$ ha & 10,9 & 6,5 & 2,0 & 6,7 & 5,9 & 7,69 & 293,93 & 26,97 & 2,0 \\
\hline $5^{\circ}$ pulv. fungicida & $\mathrm{n}^{\circ} \mathrm{ha}$ & 10,9 & 6,5 & 7,4 & 6,7 & 5,9 & 7,69 & 854,93 & 78,43 & 5,7 \\
\hline $6^{\circ}$ pulv. fungicida & $\mathrm{n}^{\circ} \mathrm{ha}$ & 10,9 & 6,5 & 7,4 & 6,7 & 5,9 & 7,69 & 854,93 & 78,43 & 5,7 \\
\hline
\end{tabular}




\begin{tabular}{|c|c|c|c|c|c|c|c|c|c|c|}
\hline Aplic. uréia & $\mathrm{n}^{\circ}$ ha & 10,9 & 6,5 & 12,5 & 6,7 & 4,9 & 7,69 & $1.393,90$ & 127,88 & 9,3 \\
\hline $\begin{array}{l}7^{\circ} \text { pulv. (secagem } \\
\text { pré-colheita) }\end{array}$ & $\mathrm{n}^{\circ}$ ha & 10,9 & 6,5 & 7,6 & 6,7 & 5,9 & 7,69 & 881,49 & 80,87 & 5,9 \\
\hline $\begin{array}{l}\text { Colheita } \\
\text { (terceização) }\end{array}$ & $\mathrm{n}^{\circ}$ ha & 10,9 & & & & & & $2.835,00$ & 260,09 & 18,8 \\
\hline Frete (terceização) & $\mathrm{n}^{\circ}$ ha & 10,9 & & & & & & 437,83 & 40,17 & 2,9 \\
\hline Total & $\mathrm{n}^{\circ}$ ha & 10,9 & 100 & 100 & 100 & 100 & 100 & $15.061,70$ & $1.381,81$ & 100,0 \\
\hline \multirow[b]{3}{*}{ Ativividades } & \multirow{3}{*}{$\begin{array}{l}\text { Direc. } \\
\text { de } \\
\text { custos }\end{array}$} & \multirow[b]{3}{*}{ Quant } & \multicolumn{5}{|c|}{ Recursos } & \multirow{2}{*}{$\begin{array}{l}\text { Total } \\
\text { da } \\
\text { atividade }\end{array}$} & \multirow{2}{*}{$\begin{array}{l}\text { Custo } \\
\text { por } \\
\text { hectare }\end{array}$} & \multirow[b]{3}{*}{$\%$} \\
\hline & & & $\begin{array}{c}\text { Mão- } \\
\text { de- } \\
\text { obra }\end{array}$ & Materiais & Combust. & Depr. & $\begin{array}{c}\text { Óleos/filtro } \\
\text { s }\end{array}$ & & & \\
\hline & & & $\%$ & $\%$ & $\%$ & $\%$ & $\%$ & $\mathbf{R} \mathbf{S}$ & $\mathbf{R} \mathbf{S}$ & \\
\hline $1^{\circ}$ pulv. (secagem) & $\mathrm{n}^{\circ}$ ha & 10,9 & 6,5 & 3,0 & 6,5 & 5,9 & 7,69 & 392,23 & 35,98 & 2,6 \\
\hline Plantio & $\mathrm{n}^{\circ}$ ha & 10,9 & 48,4 & 49,3 & 46,7 & 53,7 & 38,46 & $5.815,56$ & 533,54 & 38,6 \\
\hline $2^{\circ}$ pulv. herbicida & $\mathrm{n}^{\circ}$ ha & 10,9 & 6,5 & 8,8 & 6,7 & 5,9 & 7,69 & $1.007,93$ & 92,47 & 6,7 \\
\hline $3^{\circ}$ pulv. inseticida & $\mathrm{n}^{\circ}$ ha & 10,9 & 6,5 & 2,0 & 6,7 & 5,9 & 7,69 & 293,93 & 26,97 & 2,0 \\
\hline $4^{\circ}$ pulv. inseticida & $\mathrm{n}^{\circ}$ ha & 10,9 & 6,5 & 2,0 & 6,7 & 5,9 & 7,69 & 293,93 & 26,97 & 2,0 \\
\hline $5^{\circ}$ pulv. fungicida & $\mathrm{n}^{\circ}$ ha & 10,9 & 6,5 & 7,4 & 6,7 & 5,9 & 7,69 & 854,93 & 78,43 & 5,7 \\
\hline $6^{\circ}$ pulv. fungicida & $\mathrm{n}^{\circ}$ ha & 10,9 & 6,5 & 7,4 & 6,7 & 5,9 & 7,69 & 854,93 & 78,43 & 5,7 \\
\hline Aplic. uréia & $\mathrm{n}^{\circ}$ ha & 10,9 & 6,5 & 12,5 & 6,7 & 4,9 & 7,69 & $1.393,90$ & 127,88 & 9,3 \\
\hline $\begin{array}{l}7^{\circ} \text { pulv. (secagem } \\
\text { pré-colheita) }\end{array}$ & $\mathrm{n}^{\circ}$ ha & 10,9 & 6,5 & 7,6 & 6,7 & 5,9 & 7,69 & 881,49 & 80,87 & 5,9 \\
\hline $\begin{array}{l}\text { Colheita } \\
\text { (terceização) }\end{array}$ & $\mathrm{n}^{\circ}$ ha & 10,9 & & & & & & $2.835,00$ & 260,09 & 18,8 \\
\hline Frete (terceização) & $\mathrm{n}^{\circ}$ ha & 10,9 & & & & & & 437,83 & 40,17 & 2,9 \\
\hline Total & $\mathrm{n}^{\circ}$ ha & 10,9 & 100 & 100 & 100 & 100 & 100 & $15.061,70$ & $1.381,81$ & 100,0 \\
\hline
\end{tabular}

Quadro 5 - Cálculo do custo das atividades relacionadas à cultura do feijão

Fonte: dados da pesquisa.

A cultura do feijão se compõe de três processos de produção: plantio, tratamento de cultura em formação e colheita + frete. Esses processos se subdividem em atividades, expostas no Quadro 5. A área cultivável de feijão é equivalente a 10,9 hectares.

Os recursos mais representativos em termos de valores foram os materiais, com $71 \%$ da estrutura total de custos. O levantamento de custos por atividades na cultura da soja destaca os processos mais consumidores de recursos, são eles: o plantio e a colheita ( $56 \%$ dos custos de produção). Destaca-se com $38 \%$ o plantio, a colheita com $18 \%$ e a aplicação de uréia com $9 \%$.

No Quadro 6 apresenta-se o cálculo do custo das atividades relacionadas à cultura do milho, evidenciando-se as atividades, os direcionadores de recursos e de atividades com as respectivas distribuições de valores e, por último, o custeio da cultura de milho.

\begin{tabular}{|c|c|c|c|c|c|c|c|c|c|c|}
\hline \multirow[b]{3}{*}{ Atividades } & \multirow{3}{*}{$\begin{array}{l}\text { Direc. } \\
\text { de } \\
\text { custos }\end{array}$} & \multirow[b]{3}{*}{ Quant } & \multicolumn{5}{|c|}{ Recursos } & \multirow{2}{*}{$\begin{array}{l}\text { Total } \\
\text { da } \\
\text { atividade }\end{array}$} & \multirow{2}{*}{$\begin{array}{l}\text { Custo } \\
\text { por } \\
\text { hectare }\end{array}$} & \multirow[b]{3}{*}{$\%$} \\
\hline & & & $\begin{array}{l}\text { Mão- } \\
\text { de- } \\
\text { obra }\end{array}$ & Materiais & Combust. & Depr. & Óleos/filtros & & & \\
\hline & & & $\%$ & $\%$ & $\%$ & $\%$ & $\%$ & $\mathrm{R} \$$ & $\mathrm{R} \$$ & \\
\hline Arado sub-solador & $\mathrm{n}^{\circ}$ ha & 10,9 & 31,3 & 0,0 & 43,2 & 26,2 & 38,5 & 738,86 & 67,79 & 4,1 \\
\hline Grade niveladora & $n^{\circ}$ ha & 10,9 & 12,5 & 0,0 & 12,1 & 13,1 & 15,4 & 267,11 & 24,51 & 1,5 \\
\hline $\begin{array}{l}1^{\circ} \text { pulv. (secagem } \\
\text { pré-plantio) }\end{array}$ & $\mathrm{n}^{\circ}$ ha & 10,9 & 3,1 & 1,2 & 3,0 & 3,6 & 3,8 & 217,27 & 19,93 & 1,2 \\
\hline plantio & $\mathrm{n}^{\circ}$ ha & 10,9 & 37,5 & 48,2 & 25,9 & 39,6 & 23,1 & $6.825,27$ & 626,17 & 37,7 \\
\hline $2^{\circ}$ pulv. inseticida & $n^{\circ}$ ha & 10,9 & 3,1 & 2,3 & 3,1 & 3,6 & 3,8 & 362,65 & 33,27 & 2,0 \\
\hline $\begin{array}{l}3^{\circ} \text { pulv. nutriente } \\
\text { vegetal }\end{array}$ & $\mathrm{n}^{\circ}$ ha & 10,9 & 3,1 & 1,2 & 3,1 & 3,6 & 3,8 & 218,65 & 20,06 & 1,2 \\
\hline $\begin{array}{l}4^{\circ} \text { pulv. com } \\
\text { defensivos }\end{array}$ & $n^{\circ}$ ha & 10,9 & 3,1 & 1,9 & 3,1 & 3,6 & 3,8 & 308,65 & 28,32 & 1,7 \\
\hline
\end{tabular}




\begin{tabular}{|l|l|l|l|l|l|l|l|r|r|r|}
\hline Aplic. de uréia & $\mathrm{n}^{\circ}$ ha & 10,9 & 3,1 & 33,2 & 3,1 & 3,0 & 3,8 & $4.282,12$ & 392,85 & 23,7 \\
\hline $5^{\circ}$ pulv. herbicida & $\mathrm{n}^{\circ}$ ha & 10,9 & 3,1 & 12,1 & 3,3 & 3,6 & 3,8 & $1.607,57$ & 147,48 & 8,9 \\
\hline $\begin{array}{l}\text { Colheita } \\
\text { (tercerização) }\end{array}$ & $\mathrm{n}^{\circ}$ ha & 10,9 & & & & & & & & \\
\hline Fete (tercerização) & $\mathrm{n}^{\circ}$ ha & 10,9 & & & & & & $1.241,60$ & 113,91 & 6,9 \\
\hline Total & $\mathrm{n}^{\circ}$ ha & $\mathbf{1 0 , 9}$ & $\mathbf{1 0 0}$ & $\mathbf{1 0 0}$ & $\mathbf{1 0 0}$ & $\mathbf{1 0 0}$ & $\mathbf{1 0 0}$ & $\mathbf{1 8 . 0 9 6 , 7 5}$ & $\mathbf{1 . 6 6 0 , 2 5}$ & $\mathbf{1 0 0}$ \\
\hline
\end{tabular}

Quadro 6 - Cálculo do custo das atividades relacionadas à cultura do milho

Fonte: dados da pesquisa.

A cultura do milho se compõe de quatro processos de produção: preparo do solo, plantio, tratamento de cultura em formação e colheita + frete. Esses processos se subdividem em atividades, expostas no Quadro 6. A área cultivável de milho é equivalente a 10,9 hectares.

Os recursos mais representativos em termos de valores foram os materiais, com $71 \%$ da estrutura total de custos. O levantamento de custos por atividades na cultura da soja destaca os processos mais consumidores de recursos, são eles: o plantio, a aplicação de ureia e a colheita (73\% dos custos de produção). Destaca-se com $38 \%$ o plantio, aplicação de ureia com $24 \%$ e a colheita com $11 \%$.

\subsection{ANÁLISE DOS RESULTADOS DAS CULTURAS COM BASE NO CUSTEIO $\mathrm{ABC}$}

Para o acompanhamento dos custos na propriedade rural estudada, sugeriu-se o uso de um instrumento de captação e registro de dados, uma caderneta de campo conforme abordado por Lopes e Carvalho (2000). A caderneta serviria como meio de sustentação de informações ao sistema de custos. Contudo, ela não foi utilizada, sob alegação do excesso do volume de trabalho, sendo considerada de pouca prioridade no âmbito da realidade das operações cotidianas da propriedade rural.

Em relação aos resultados das culturas com base na aplicação do custeio $\mathrm{ABC}$, constou-se que os altos preços contribuíram para que os gastos com insumos chegassem a representar em média nas três culturas $40 \%$ da estrutura total de custos. A mão-deobra representou em média nas três culturas $40 \%$ da estrutura total de custos. A colheita representou em média nas três culturas $20 \%$ da estrutura total de custos.

A lucratividade da cultura da soja foi de $37 \%$. Houve uma pequena queda de produtividade em função da estiagem. Variáveis de mercado também afetaram o resultado, particularmente a aquisição de insumos a um custo elevado em decorrência da alta do dólar.

Por outro lado, o câmbio desfavorável proporcionou a venda do produto final abaixo do preço praticado em anos anteriores.

A cultura do feijão é destaque do período pela sua rentabilidade e lucratividade. Um custo por hectare de $\mathrm{R} \$ 1.381,81$, alta produtividade e bons preços praticados no mercado fizeram com que a margem de lucro chegasse a $44 \%$ sobre a receita bruta.

O resultado da cultura do milho ficou prejudicado pelos elevados preços dos insumos, ocasionados pelas flutuações desfavoráveis do dólar. Houve uma queda de produtividade em função da estiagem. Foi necessário aplicar mais uréia, material necessário para aumentar a produtividade do milho, este insumo corresponde à $24 \%$ dos custos totais. As políticas cambiais do governo proporcionaram a venda do produto final abaixo do preço praticado em anos anteriores. Diante destes aspectos a cultura do milho apresentou prejuízo de $\mathrm{R} \$ 2.271,00$.

Do exposto depreende-se que os resultados das três culturas foram impactados por diversos fatores, cuja síntese apresenta-se no Quadro 7. 


\begin{tabular}{|c|c|c|c|}
\hline Produtos & Soja & Milho & Feijãa \\
\hline $\begin{array}{l}\text { Custos dos insumos de } \\
\text { produção }\end{array}$ & Custos elevados & Custos elevados & Custos elevados \\
\hline Produtividade & $\begin{array}{l}\text { Razoável } \\
\text { produtividade }\end{array}$ & Baixa produtividade & Boa produtividade \\
\hline Preço de venda & $\begin{array}{l}\text { Preço abaixo da } \\
\text { expectativa }\end{array}$ & $\begin{array}{l}\text { Preço abaixo da } \\
\text { expectativa }\end{array}$ & Bom preço de venda \\
\hline
\end{tabular}

Quadro 7 - Análise das culturas de soja, milho e feijão

Fonte: dados da pesquisa.

A cultura do milho se tornou inviável economicamente no período estudado. Seu custo por hectare girou em torno de $\mathrm{R} \$ 1.660,25$, o maior das três culturas. No entanto, sua baixa produtividade decorrente da estiagem e seus altos custos de produção fizeram com que a receita não cobrisse os custos de produção, tendo assim um prejuízo de $\mathrm{R} \$$ 236,21 por hectare. No processo de produção da cultura do milho, destacam-se as atividades: plantio, aplicação de uréia e a colheita, que foram responsáveis por $72,6 \%$ dos custos de produção.

A soja se mostrou dentro dos patamares esperados. Cabe destacar que dentre as três culturas, a soja é a que teve menor custo de produção por hectare, que foi de R\$ 880,54 . No total dos 9,68 hectares obteve-se uma receita bruta de $\mathrm{R} \$ 13.795,00$, superando os custos e as despesas que foram de $\mathrm{R} \$ 8.523,64$, obtendo assim um lucro líquido de $\mathrm{R} \$ 5.271,36$ e um lucro líquido por hectare de $\mathrm{R} \$ 544,57$, que corresponde a $37 \%$ de lucratividade.

O destaque do período foi à cultura do feijão, que se mostrou altamente rentável. Sua boa produtividade e os bons preços praticados no mercado fizeram com que a margem de lucro chegasse a $44 \%$ sobre a receita bruta. Seu custo por hectare chegou a $\mathrm{R} \$ 1.381,81$, um pouco abaixo do milho. Já seu lucro líquido por hectare ficou em $\mathrm{R} \$$ 1.093,01, demonstrando dessa forma que a cultura do feijão foi a mais viável economicamente dentre as três culturas.

Ressalta-se o bom desempenho na cultura do feijão, propiciado por um clima favorável e pelos bons preços praticados no mercado, não sendo o caso da cultura do milho e da soja. Comparando a cultura do feijão, da soja e do milho, constatou-se que o feijão teve lucratividade superior ao da soja por hectare. Os custos por hectare na cultura do milho foram superiores aos da soja e do feijão. O menor custo por hectare foi da cultura da soja.

\section{CONSIDERAÇÕES FINAIS}

O objetivo do estudo foi descrever a aplicação de um sistema de gestão de custos baseado em atividades no âmbito de uma pequena propriedade rural. Para tanto foi realizada uma pesquisa exploratória, por meio de um estudo de caso, com abordagem quantitativa.

Diversas etapas foram seguidas para aplicação do sistema de gestão de custos baseado em atividades no âmbito de uma pequena propriedade rural. Primeiramente, procedeu-se o levantamento dos custos de produção das culturas da soja, feijão e milho, que são basicamente a mão-de-obra, materiais, combustíveis, depreciação e os óleos e filtros.

Em seguida efetuou-se o mapeamento das atividades para as três culturas. As atividades representam variáveis indutoras de gastos, que requerem mecanismos de acomodação dos recursos consumidos para fins de esquematização da lógica de funcionamento do custeio $\mathrm{ABC}$, denominados direcionadores de recursos. 
A identificação dos direcionadores de recursos foi realizada na seqüência, os quais são instrumentos de rastreamento e de quantificação dos gastos consumidos pelas atividades.

Após identificaram os direcionadores de atividades, para alocação dos custos das atividades aos objetos de custeio. Nas três culturas o parâmetro utilizado para alocação dos custos foi a área cultivável de cada cultura.

$\mathrm{Na}$ análise dos custos, observou-se a presença de vários fatores imprescindíveis e determinantes na safra, que tiveram reflexos na produção e na lucratividade das culturas e da propriedade como um todo. Dentre esses fatores citam-se a estiagem, os elevados custos em função do dólar em alta e a venda de alguns produtos por valores abaixo da expectativa.

Quanto à aplicação do sistema de gestão de custos baseado em atividades no âmbito de uma pequena propriedade rural, conclui-se que a simulação para o estudo de caso foi possível num primeiro momento. Contudo, a sua operacionalização ainda se apresenta frágil, devido à dependência quase que exclusiva dos membros da família do pequeno agricultor para o fornecimento dos dados, que não os têm na lista de prioridades das tarefas do cotidiano.

Embora o estudo de caso tenha a limitação de não se poder generalizar as conclusões, considera-se válida a aplicação realizada. No entanto, recomenda-se a reaplicação do estudo em outras propriedades rurais de pequeno porte para fins comparativos. Recomenda-se também um estudo sobre métodos de análise hierárquica, de forma a analisar a relação entre os direcionadores de custos propostos e as atividades identificadas em cada cultura.

\section{REFERENCIAS}

ATKINSON, A. A. et al. Contabilidade gerencial. São Paulo: Atlas, 2000.

BORNIA, A. C. Análise gerencial de custos em empresas modernas. Porto Alegre: Boockman, 2002.

BRIMSON, J. A. Contabilidade por atividades: uma abordagem de custeio baseado em atividades. São Paulo: Atlas, 1996.

BRUNI, A. L.; FAMA, R. Gestão de custos e formação de preços: com aplicações na calculadora HP 12c e excel. 3. ed. São Paulo: Atlas, 2004.

CHING, H. Y. Gestão baseada em custeio por atividades. 3. ed. São Paulo: Atlas, 2001.

DOMENICO, G. B. Gestão de custos baseada em atividades em um ambiente agrícola. Disponível em: <http://www.unicamp.br>. Acesso em: 13 out. 2006.

FACHIN, O. Fundamentos de metodologia. 3. ed. São Paulo: Saraiva, 2002.

GARRISON, R. H.; NOREEN, E. W. Contabilidade gerencial. 9. ed. Rio de Janeiro: LTC, 2001.

GIL, A. C. Métodos e técnicas de pesquisa social. 5. ed. São Paulo: Atlas, 1999. 
KAPLAN, R. S; COOPER, R. Custo e desempenho: administre seus custos para ser mais competitivo. São Paulo: Futura, 1998.

Custo e efeito. Barcelona: Ed. 2000, 1999.

LEONE, G. S. G. Curso de contabilidade de custos. São Paulo: Atlas, 1997.

LOPES, M. A.; CARVALHO, F. de M. Custo de produção do leite. Boletim Agropecuário, Lavas: UFLA, n.33, 2000.

MAHER, M. Contabilidade de custos: criando valor para a administração. São Paulo: Atlas, 2001.

MARION, J. C. Contabilidade e controladoria em agribusiness. São Paulo: Atlas, 1996.

MARTINS, E. Contabilidade custos. 8. ed. São Paulo: Atlas, 2001.

MERRIAN, S. B. Case study research in education: a qualitative approach. São Francisco: Jossey Bass, 1988.

NAKAGAWA, M. ABC: custeio baseado em atividades. 2. ed. São Paulo: Atlas, 2001.

RAUPP, F. M.; BEUREN, I. M. Metodologia da pesquisa aplicável às ciências sociais. In: BEUREN, I. M. (org.). Como elaborar trabalhos monográficos em contabilidade: teoria e prática. 2. ed. São Paulo: Atlas, 2004, p.76-97.

RICHARDSON, Roberto Jarry. Pesquisa social: métodos e técnicas. $3^{\mathrm{a}}$ ed. São Paulo: Atlas, 1999.

SAKURAI, M. Gerenciamento integrado de custos. Tradução de Adalberto Ferreira das Neves e revisão técnica de Eliseu Martins. São Paulo: Atlas, 1997.

SHANK, J. K.; GOVINDARAJAN, V. Gestão estratégica de custos: a nova ferramenta para a vantagem competitiva. Rio de Janeiro: Campus, 1995.

SOUZA, R. et al. A administração da fazenda. São Paulo: Globo, 1992. 